\title{
Occurrence of autoimmune diseases and autoantibodies in multicase rheumatoid arthritis families
}

\author{
D J WALKER, M GRIFFITHS, AND I D GRIFFITHS \\ From the Department of Rheumatology, Royal Victoria Infirmary, Newcastle upon Tyne
}

SUMmARY The presence of autoimmune diseases and autoantibodies has been studied in 237 individuals from 17 families with two or more members affected by rheumatoid arthritis (RA). Hyperthyroidism occurred significantly more frequently than in a local control population $(p<0 \cdot 05)$, but if the RA cases were excluded this significance was lost. Thyroid cytoplasmic and microsomal antibodies were significantly more common $(p<0 \cdot 001)$, and this remained true if RA sufferers were excluded $(\mathrm{p}<0 \cdot 01)$. The prevalence of both clinical thyroid disease and circulating thyroid autoantibodies was similar in the families where RA was associated with HLA-DR4 and in those where no DR4 association was observed. RA and immune thyroid disease may, therefore, share a common inherited factor, but this is unlikely to be at the HLA-DR locus. Antinuclear factor (ANF) was found in association with RA and with HLA-DR3 within the RA group $(p<0 \cdot 02)$. Relatives of RA sufferers did not show any excess of ANF positivity. The prevalence of pernicious anaemia (PA) and gastric parietal cell antibody did not differ from the expected.

Key words: HLA, autoimmunity, genetics.

Both familial clustering of RA and an association with the major histocompatibility complex (MHC) antigen, HLA-DR4, are well recognised. ${ }^{\prime}$ Despite these observations, the role of inheritance in the aetiology of RA remains unclear. Susceptibility to RA may be specific to that disease or part of a common autoimmune disease susceptibility. In the latter case this could allow the development of different autoimmune diseases depending upon trigger factors or on other inherited factors. If this is the case then autoimmune disorders and autoantibodies should be found in higher frequency in the relatives of RA sufferers. A recent family study of $\mathrm{RA}^{2}$ has shown that in those families where RA was not inherited with DR4 there was a high incidence of autoimmune thyroid disease in the non-arthritic relatives (five out of seven families). The authors' interpretation of this observation is that RA can be inherited with HLA-DR4 or it can be separately

Accepted for publication 20 August 1985.

Correspondence to Dr D J Walker. Department of Rheumatology, Royal Victoria Infirmary. Queen Victoria Road. Newcastle upon Tyne NE1 4LP. inherited along with susceptibility to autoimmune thyroid disease. Type 1 diabetes mellitus has also been found in increased frequency in relatives of RA sufferers. ${ }^{3}$ We have studied autoimmune diseases and autoantibodies in a population of multicase RA families. Our purpose was to document any alteration in the expected frequencies and to compare this with the inheritance of HLA antigens and haplotypes.

\section{Patients and methods}

We have studied 17 families with two or more individuals affected by RA. Probands were ascertained from patients attending the Department of Rheumatology. Newcastle upon Tyne. Seventeen probands and 220 blood relatives over the age of 15 years were assessed. All individuals were interviewed and examined clinically. Symptoms and signs of RA were noted and diagnosis was standardised by American Rheumatism Association criteria. ${ }^{4}$ Forty eight family members had classical or definite RA. The history of other diseases was taken, with 
Table 1 Prevalence of immune diseases and associated HLA-DR types in the probands and their blood relatives

\begin{tabular}{|c|c|c|c|c|c|c|c|c|c|c|c|c|c|c|c|}
\hline \multirow[t]{2}{*}{ Disease } & \multicolumn{2}{|c|}{ Total } & \multicolumn{2}{|c|}{ Whickham pop. } & \multirow{2}{*}{$\begin{array}{l}\text { No with } \\
\text { class. def. } R A\end{array}$} & \multicolumn{10}{|c|}{ No with HLA-DR types: } \\
\hline & No & $\%$ & No & $\%$ & & $l$ & 2 & 3 & 4 & 5 & 6 & 7 & 8 & 9 & 10 \\
\hline Hyperthyroid & $7 \div$ & 3 & 30 & 1 & 2 & 1 & 2 & 1 & 6 & - & - & 2 & $!$ & - & - \\
\hline Hypothyroid & 2 & $0 \cdot 8$ & 22 & 0.8 & 2 & 1 & - & - & 2 & - & - & - & - & - & - \\
\hline Pernicious anaemia & 3 & $1 \cdot 3$ & & & 3 & 1 & 1 & 1 & 3 & - & - & - & - & - & - \\
\hline IDDM $^{*}$ & 1 & $0 \cdot 4$ & & & () & 1 & - & - & 1 & - & - & - & - & - & - \\
\hline MODM* & 4 & $1 \cdot 7$ & & & 1 & - & - & - & 3 & 1 & 1 & - & - & - & - \\
\hline Total & 237 & & 2779 & & 48 & 58 & 37 & 49 & 158 & 9 & 27 & 60 & 5 & - & 2 \\
\hline
\end{tabular}

*IDDM=insulin dependent diabetes mellitus: MODM=maturity onset diabetes mellitus.

+Whickham $\mathrm{p}<0 \cdot(05$.

particular reference to thyroid disease, diabetes mellitus, and pernicious anaemia. Blood was taken for thyroid cytoplasmic and microsomal antibodies, gastric parietal cell antibodies, antinuclear factor antibodies, antimitochondrial antibodies, and antismooth muscle antibodies. Thyroid cytoplasmic antibodies, gastric parietal cell antibodies, antinuclear factor antibodies, antimitochondrial antibodies, and antismooth muscle antibodies were tested for by a standard indirect immunofluorescent technique with Wellcome FITC antihuman immunoglobulin for labelling. Thyroid microsomal antibodies were tested for with the Fujirebio kit (FD-202). HLA typing was performed by a standard lymphocytotoxic assay as described by Dewar. ${ }^{5}$ DR antigens 1-10 were tested for. HLA haplotypes were defined from the pedigree data. The haplotype most frequently shared by the RA sufferers in individual families could then be found. ${ }^{6}$ These are referred to as the 'RA haplotypes' and are specific to each family.

A local control population for thyroid disease and autoantibodies was available in the form of the Whickham survey. ${ }^{7}$ Statistical analysis for association was carried out by the $\chi^{2}$ test.

\section{Results}

IMMUNE DISEASES

A summary of the prevalence of autoimmune disease is shown in Table 1. A history of hyperthyroidism was given by seven individuals, two of whom had RA. Five of the seven had the onset of $\infty$ their thyroid disease below the age of 45 , the remaining two had onset at the age of 55 and 60 . years. When compared with the Whickham population this was a significant excess $(p<0 \cdot 05)$. If, however, RA sufferers were excluded then this

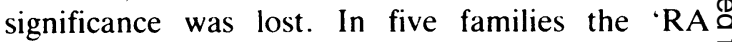
haplotype' did not contain HLA-DR4. In only one $\overrightarrow{\overrightarrow{0}}$ of these families did hyperthyroidism occur. Hyper- $\exists$ thyroidism occurred in four of the remaining $12 \ni$ families.

There were no other significant excesses for any other autoimmune diseases. One case of primary biliary cirrhosis, one case of chronic active hepatitis, and one case of myasthenia gravis occurred in the family population. The prevalence of diabetes mellitus in this population is an underestimate as in one family a branch containing three diabetics refused to $\triangle$ be studied. No significant DR association was shown

Table 2 Prevalence of autoantibodies and associated HLA-DR types in the probands and their blood relatives

\begin{tabular}{|c|c|c|c|c|c|c|c|c|c|c|c|c|c|c|}
\hline \multirow[t]{2}{*}{ Autoantibodies } & \multicolumn{2}{|c|}{ Total } & \multirow{2}{*}{$\begin{array}{l}\text { Whickham pop. } \\
(\%+v e)\end{array}$} & \multirow{2}{*}{$\begin{array}{l}\text { No with } \\
\text { class. def. } R A\end{array}$} & \multicolumn{10}{|c|}{ No with $H L A-D R$ types: } \\
\hline & No & $\%$ & & & 1 & 2 & 3 & 4 & 5 & 6 & 7 & 8 & 9 & 10 \\
\hline Thyroid cytoplasmic & $33+$ & 14 & 7 & 9 & 7 & 6 & 3 & 23 & 1 & 7 & 9 & $3^{* *}$ & - & 1 \\
\hline Thyroid microsomal & $34+$ & 14 & 5 & 10 & 7 & 7 & 4 & 25 & 1 & 7 & 9 & $3^{* *}$ & - & 1 \\
\hline Gastric parictal cell & 12 & 5 & 6 & 6 & 2 & 4 & 2 & 9 & - & - & 4 & - & - & - \\
\hline Antinuclear factor & $19+$ & 8 & 4 & 12 & 6 & 0 & $8^{* * *}$ & 14 & 1 & 1 & $1^{*}$ & - & - & - \\
\hline
\end{tabular}

${ }^{*} v$ rest of family $\mathrm{p}<0.05 ;{ }^{* *} v$ rest of family $\mathrm{p}<0.01 ;{ }^{* * *} v$ rest of family $\mathrm{p}<0.001$.

$\dagger v$ Whickham $\mathrm{p}<0.001$. 
Table 3 Prevalence of autoantibodies and associated $H L A-D R$ types in blood relatives without RA

\begin{tabular}{|c|c|c|c|c|c|c|c|c|c|c|c|c|}
\hline \multirow[t]{2}{*}{ Autoantibodies } & \multicolumn{2}{|l|}{ Total } & \multicolumn{10}{|c|}{ No with $H L A-D R$ types: } \\
\hline & No & $\%$ & 1 & 2 & 3 & 4 & 5 & 6 & 7 & 8 & 9 & 10 \\
\hline Thyroid cytoplasmic & $24+$ & 13 & 4 & 3 & 3 & 15 & 1 & 5 & 8 & $3^{* *}$ & - & 1 \\
\hline Thyroid microsomal & $25 \div \div$ & 13 & 4 & 4 & 3 & 16 & 1 & 5 & 8 & $3^{* *}$ & - & 1 \\
\hline Gastric parietal cell & 6 & 3 & 1 & 2 & - & 4 & - & - & $4^{*}$ & - & - & - \\
\hline Antinuclear factor & 7 & 4 & 2 & - & 2 & 6 & - & - & 1 & - & - & - \\
\hline
\end{tabular}

${ }^{*} v$ rest of family $\mathrm{p}<0 \cdot 05 ;{ }^{* *} v$ rest of family $\mathrm{p}<0 \cdot 01$.

$+v$ Whickham $\mathrm{p}<0.01$; $+t v$ Whickham $\mathrm{p}<0 \cdot 001$.

with any autoimmune disease by comparison with the rest of the family.

\section{A UTOANTIBODIES}

Table 2 summarises the results of the autoantibodies found in the family population. Thyroid cytoplasmic and thyroid microsomal antibodies were found in increased frequency, as compared with the Whickham population. This excess remained if the RA sufferers were excluded (Table 3 ). Of the five families in which RA was inherited with a non-DR4 haplotype, four had relatives with thyroid autoantibodies compared with nine of the 12 DR4 positive haplotype families. ANF was found in increased numbers, but if the RA group was excluded the prevalence was the same as in the Whickham survey (i.e., $5 \%$ ).

Thyroid autoantibodies were found to be associated with HLA-DR8 in this population. This association was retained if RA was excluded. As this was an unexpected association it may be the result of a secondary statistical error, and a further study would be necessary to confirm or refute this. ANF was significantly associated with HLA-DR3 in the whole population $(p<0.001)$, and this association is sufficiently strong to exclude a secondary statistical error. The association of ANF with DR3 occurred in the RA group, where six of the 12 RA sufferers positive for ANF possessed DR3 compared with five of the 39 ANF negative RA individuals $(p<0.01)$. There was no association of DR3 with non-RA ANF positivity. HLA-DR7 was found significantly less frequently in the ANF positive group. Gastric parietal cell positivity in the non-RA group was weakly associated with HLA-DR7.

Within the family population the 'RA haplotypes' were not significantly associated with any autoimmune disease except RA. Similarly, no association was found with the autoantibodies except for ANF, and this association was lost if RA was excluded.

\section{Discussion}

Autoimmune diseases are well recognised as occurring more frequently together than could be expected by chance. ${ }^{8}$ One possible explanation for this is the inheritance of a common gene predisposing to autoimmunity, the type of disease developed depending on other factors either inherited or environmental. The inheritance of many autoimmune diseases with the HLA-B8-Dw3-DR3 haplotype ${ }^{9}$ is in favour of this. The association of RA with HLA-DR4 is evidence against RA being included in this common inheritance. An increase of thyroid disease in the families of RA sufferers has, however, previously been reported, ${ }^{2}$ though this was only in families in which RA was inherited with a haplotype not containing HLA-DR4. The increased prevalence of hyperthyroidism in our families was dependent upon its occurrence with RA. The hyperthyroidism did not occur more frequently in the 'non-DR4' families in our study and if our data are added to those of Grennan et al. ${ }^{2}$ the association with 'non-DR4' families is lost. Hypothyroidism was not found in excess and cannot therefore be included in this shared inheritance.

The prevalence of thyroid microsomal and cytoplasmic antibodies was greatly increased in the family population by comparison with the Whickham population, and this excess was independent of an association with RA. The data from the Whickham survey suggest that thyroid autoantibodies are related to thyroid disease. They are found in association with both hyperthyroidism and hypothyroidism. The finding of an increase of thyroid autoantibodies in the relatives of RA sufferers therefore supports a common inherited factor for both RA and immune thyroid disease. Previous studies have shown different HLA associations for RA and autoimmune thyroid disease; RA being associated with HLA-DR4 and autoimmune thyroid disease with HLA-DR3. ${ }^{10}$ Therefore, it would seem likely that any common inherited factor is not at the DR locus. This is supported by our observation that thyroid disease and thyroid autoantibodies were not associated with the 'RA haplotype', and it is likely that any common inherited factor is not in the MHC.

PA and gastric parietal cell antibodies were not 
found in either increased or decreased frequency in our population. PA has been shown to be associated with HLA-DR $2^{11}$ and so might have been expected to be decreased. Gastric parietal cell antibodies are commonly found in association with thyroid autoantibodies $^{9}$ and so might have been expected to be increased.

Antinuclear factor was found in association with HLA-DR3 in the RA population, but in the rest of the family it was neither associated with DR3 nor found in excess. HLA-Dw3-DR3 has been found in association with Sjögren's syndrome. ${ }^{12}$ adverse reactions to gold and penicillamine, ${ }^{13}$ and high titre rheumatoid factor seropositivity. ${ }^{14}$ Our observed association with ANF would further support the concept of DR3 as a hyperimmune gene. Systemic lupus erythematosus was not found in any family members.

Diabetes mellitus was not found in excess in this study as might have been expected from its association with HLA-DR3 and DR4. ${ }^{15}$ Our figures, however, are an underestimate of the true prevalence as at least three diabetics refused to take part in the study.

Our data, therefore, support a common inherited factor between RA and immune thyroid disease, or thyroid antibody formation, but do not support association with any other autoimmune diseases.

We would like to thank Dr Tunbridge and his colleagues for allowing us to see the original Whickham data. We would also like to thank Mrs P McArdle for performing the autoantibody tests. Dr A Collins for tissue typing, and Miss A M McAuley for secretarial assistance. MG was supported by an Arthritis and Rheumatism Council project grant.

\section{References}

1 Stastny P. Association of the B cell alloantigen DRw4 with rheumatoid arthritis. $N$ Engl J Med 1978: 298: 869-71.

2 Grennan D M. Dyer P. Dodds W. et al. Clinical and 7 immunogenetic studies in multicase rheumatoid families. $Q J$ Med New Ser 1984; C111: 479-85.

3 Thomas D J B, Young A. Gorsuch A N, Bottazzo G F, Cudworth A G. Evidence for an association between rheumatoid arthritis and auto-immune endocrine disease. Ann Rheum Dis 1983: 42: 297-300.

4 Ropes M W. Bennett G A. Cobb S. Jacox R. Jessar R A. Revision of diagnostic criteria for rheumatoid arthritis. Bull Rheum Dis 1958; 9: 175-6.

5 Dewar P J. HLA antigens. Clin Rheum Dis 1983: 9: 103-5.

6 Walker D J, Griffiths M. Dewar P, et al. Association of MHC antigens with susceptibility to and severity of rheumatoid arthritis in multicase families. Ann Rheum Dis 1985; 44: 519-25.

7 Tunbridge W M G. Evered D C. Hall R. et al. The spectrum of thyroid disease in a community: the Whickham survey. Clin Endocrinol 1977; 7: 481-93.

8 Doniach D. Bottazzo G F. Russell R C G. Goitrous autoimmune thyroiditis (Hashimoto's disease). In: Evered D. Hall R. cds. Clin Endocrinol Metab 1979; 8: 63-80.

9 Friedman J M. Fialkow P J. The genetics of Graves' disease Clin Endocrinol Metab 1978: 7: 47-65.

10 Thorsby E. Segaard E. Solem J H. Kornstad L. The frequency of major histocompatibility antigens (SD \& LD) in thyrotoxicosis. Tissue Antigens 1975: 6: 54-5.

11 Harris R. HLA antigens. In: Medicine series. Oxford Medical Education (International) 1981-1983: 1: 226-30.

12 Cushed P M. Kassan S S, Opelz G. Moutsopoulos H M, Terasaki P I. Sjögren's syndrome associated with HLA-Dw3. N Engl J Med 1977; 296: 895-7.

13 Panayi G S. Wooley P. Batchelor J R. Genetic basis of rheumatoid disease: HLA antigens, disease manifestation and toxic reactions to drugs. $\mathrm{Br}$ Med J 1978; ii: 1326-8.

14 Stastny P. Rheumatoid arthritis. In: Terasaki P. ed. Histocompatibility testing. Los Angeles: UCLA Press, 1980: 681-6.

15 Cudworth A G. Wolf E. The genetic susceptibility to type I (insulin-dependent) diabetes mellitus. Clin Endocrinol Metab 1982: 11: 389-408. 